\title{
ON A MORE ACCURATE HILBERT-TYPE INEQUALITY INVOLVING THE PARTIAL SUMS
}

\author{
BING HE, YANRU ZHONG* AND BICHENG YANG
}

Abstract. By means of the weight coefficients, Hermite-Hadamard's inequality, the Euler-Maclaurin summation formula and Abel's summation by parts formula, a more accurate Hilbert-type inequality with the partial sums is given. The equivalent conditions of the best possible constant factor related to several parameters and some particular inequalities are also obtained.

Mathematics subject classification (2020): 26D15, 47A05.

Keywords and phrases: Weight coefficient, Euler-Maclaurin summation formula, Hilbert-type inequality, parameter, partial sum.

\section{REFERENCES}

[1] G. H. Hardy, J. E. Littlewood and G. Polya, Inequalities, Cambridge University Press, Cambridge, 1934.

[2] M. KRnić AND J. PEČARIĆ, Extension of Hilbert's inequality, J. Math. Anal., Appl. 324 (1), $150-160$ (2006).

[3] B. YANG, On a generalization of Hilbert double series theorem, J. Nanjing Univ. Math. Biquarterly, 18 (1), 145-152, 2001.

[4] V. Adiyasuren, T. Batbold, L. E. Azar, A new discrete Hilbert-type inequality involving partial sums, Journal of Inequalities and Applications, 2019:127, 2019.

[5] B. C. YANG, The norm of operator and Hilbert-type inequalities, Science Press, Beijing, China, 2009.

[6] M. Krnić And J. PEČArić, General Hilbert's and Hardy's inequalities, Mathematical inequalities \& applications, 8 (1), 29-51 (2005).

[7] I. PERIĆ AND P. VUKOVIĆ, Multiple Hilbert's type inequalities with a homogeneous kernel, Banach Journal of Mathematical Analysis, 5 (2), 33-43 (2011).

[8] Q. L. HuAng, A new extension of Hardy-Hilbert-type inequality, Journal of Inequalities and Applications (2015), 2015: 397.

[9] B. HE, A multiple Hilbert-type discrete inequality with a new kernel and best possible constant factor, Journal of Mathematical Analysis and Applications, 431, 990-902 (2015).

[10] J. S. XU, Hardy-Hilbert's inequalities with two parameters, Advances in Mathematics, 36 (2), 63-76 (2007).

[11] Z. T. XIE, Z. ZENG AND Y. F. Sun, A new Hilbert-type inequality with the homogeneous kernel of degree -2, Advances and Applications in Mathematical Sciences, 12 (7), 391-401 (2013).

[12] Z. Zhen, K. Raja Rama Gandhi And Z. T. XIE, A new Hilbert-type inequality with the homogeneous kernel of degree -2 and with the integral, Bulletin of Mathematical Sciences and Applications, 3 (1), 11-20 (2014).

[13] D. M. XIN, A Hilbert-type integral inequality with the homogeneous kernel of zero degree, Mathematical Theory and Applications, 30 (2), 70-74 (2010).

[14] L. E. AzAR, The connection between Hilbert and Hardy inequalities, Journal of Inequalities and Applications, 2013: 452, 2013.

[15] V. Adiyasuren, T. BAtbold and M. KRnić, Hilbert-type inequalities involving differential operators, the best constants and applications, Math. Inequal. Appl., 18, 111-124 (2015).

[16] M. TH. Rassias, And B. C. YAnG, On half-discrete Hilbert's inequality, Applied Mathematics and Computation, 220, 75-93 (2013). 
[17] B. C. YANG AND M. KRNIĆ, A half-discrete Hilbert-type inequality with a general homogeneous kernel of degree 0, Journal of Mathematical Inequalities, 6 (3), 401-417 (2012).

[18] M. TH. RASSIAS AND B. C. YANG, A multidimensional half-discrete Hilbert-type inequality and the Riemann zeta function, Applied Mathematics and Computation, 225, 263-277 (2013).

[19] M. TH. RASSIAS AND B. C. YANG, On a multidimensional half-discrete Hilbert-type inequality related to the hyperbolic cotangent function, Applied Mathematics and Computation, 242, 800-813 (2013).

[20] B. C. Yang And L. Debnath, Half-discrete Hilbert-type inequalities, World Scientific Publishing, Singapore, 2014.

[21] Y. HONG AND Y. WEN, A necessary and sufficient condition of that Hilbert type series inequality with homogeneous kernel has the best constant factor, Annals Mathematica, 37 A (3), 329-336 (2016).

[22] Y. HonG, On the structure character of Hilbert's type integral inequality with homogeneous kernel and application, Journal of Jilin University (Science Edition), 55 (2), 189-194 (2017).

[23] Y. Hong, Q. L. HuANG, B. C. YANG AND J. L. LiAO, The necessary and sufficient conditions for the existence of a kind of Hilbert-type multiple integral inequality with the non-homogeneous kernel and its applications, Journal of Inequalities and Applications (2017), 2017: 316.

[24] D. M. XIN, B. C. YANG AND A. Z. WANG, Equivalent property of a Hilbert-type integral inequality related to the beta function in the whole plane, Journal of Function Spaces, Volume 2018, Article ID2691816, 8 pages.

[25] Y. Hong, B. HE AND B. C. YANG, Necessary and sufficient conditions for the validity of Hilbert type integral inequalities with a class of quasi-homogeneous kernels and its application in operator theory, Journal of Mathematics Inequalities, 12 (3), 777-788 (2018).

[26] Z. X. HUANG AND B. C. YANG, Equivalent property of a half-discrete Hilbert's inequality with parameters, Journal of Inequalities and Applications (2018) 2018: 333.

[27] B. C. YANG, S. H. WU AND A. Z. WANG, On a reverse half-discrete Hardy-Hilbert's inequality with parameters, Mathematics, 2019, 7, 1054.

[28] A. Z. WANG, B. C. YANG AND Q. CHEN, Equivalent properties of a reverse's half-discret Hilbert's inequality, Journal of Inequalities and Applications (2019), 2019: 279.

[29] A. Z. WANG AND B. C. YANG, Equivalent property of a more accurate half-discrete Hilbert's inequality, Journal of Applied Analysis and Computation, 10 (3), 920-934 (2020).

[30] Y. Hong, J. Q. LiaO, B. C. YANG AND Q. CHEN, A class of Hilbert multiple integral inequalities with the kernel of generalized homogeneous function and its applications, Journal of Inequalities and Applications (2020), 2020: 140.

[31] B. C. YANG, S. H. WU AND Q. Chen, A new extension of Hardy-Hilbert's inequality containing kernel of double power functions, Mathematics, 2020, 8, 339, doi:10.3390/math8060894.

[32] M. TH. RASSIAS, B. C. YANG AND A. RAIGORODS KII, On the reverse Hardy-type integral inequalities in the whole plane with the extended Riemann-Zeta function, Journal of Mathematics Inequalities, 14 (2): 525-546 (2020).

[33] J. C. KuAng, Applied inequalities, Shangdong Science and Technology Press, Jinan, China, 2004. 